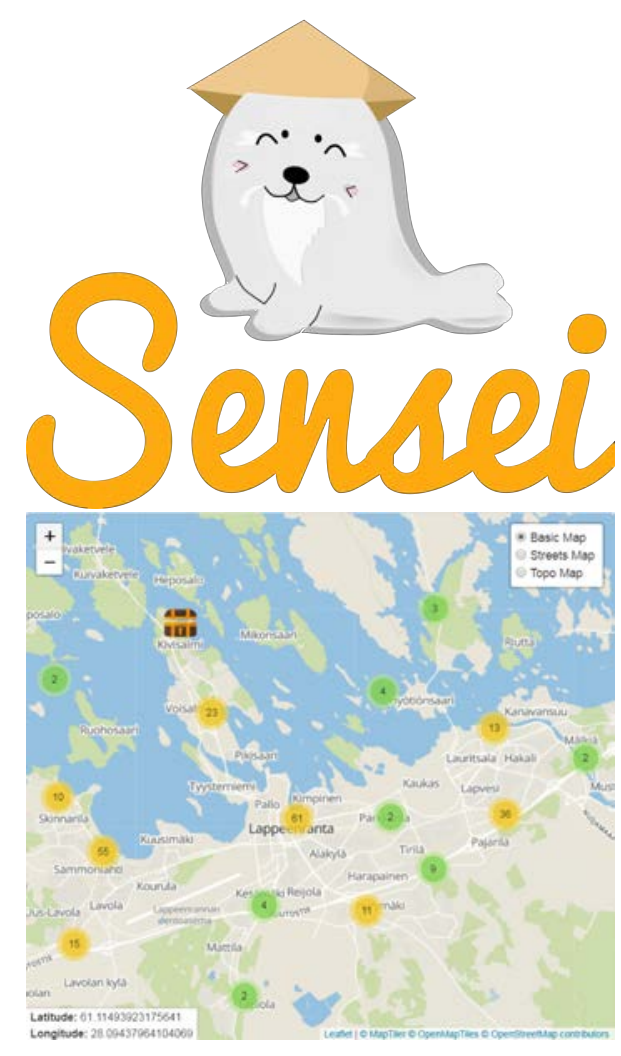

SENSEl is a community initiative involving locals, researchers, community organisations and decision makers aiming to understand the challenges they all care about. The initiative has shown how technology and participatory practices can be combined to address issues of shared concern, make sense of data and solve problems collectively.

\title{
SENSEI: Harnessing Community Wisdom for Local Environmental Monitoring in Finland
}

Victoria Palacin
LUT University
Lappeenranta, Finland
victoria.palacin@lut.fi

Maria Angela Ferrario

Lancaster University

Lancaster, UK

m.a.ferrario@lancaster.ac.uk

\section{Annika Wolff}

LUT University

Lappeenranta, Finland

name.lastname@lut.fi

\section{Niina Kupiainen}

ME-talo Lappeenranta

Lappeenranta, Finland

niina.kupiainen@nicehearts.com

\author{
Sile Ginnane \\ Liberty Bell \\ Dublin, Ireland \\ sile@libertybell.ie
}

\section{Ari Happonen \\ LUT University \\ Lappeenranta, Finland \\ name.lastname@lut.fi}

\section{Sara Piutunen}

Lappeenranta Environmental Office

Lappeenranta, Finland

Sara.Piutunen@lappeenranta.fi

Permission to make digital or hard copies of part or all of this work for personal or classroom use is granted without fee provided that copies are not made or distributed for profit or commercial advantage and that copies bear this notice and the full citation on the first page. Copyrights for third-party components of this work must be honored. For all other uses, contact the owner/author(s).

CHI'19 Extended Abstracts, May 4-9, 2019, Glagsgow, Scotland, UK

(c) 2019 Copyright held by the owner/author(s).

ACM ISBN 978-1-4503-5971-9/19/05.

https://doi.org/10.1145/3290607.3299047 


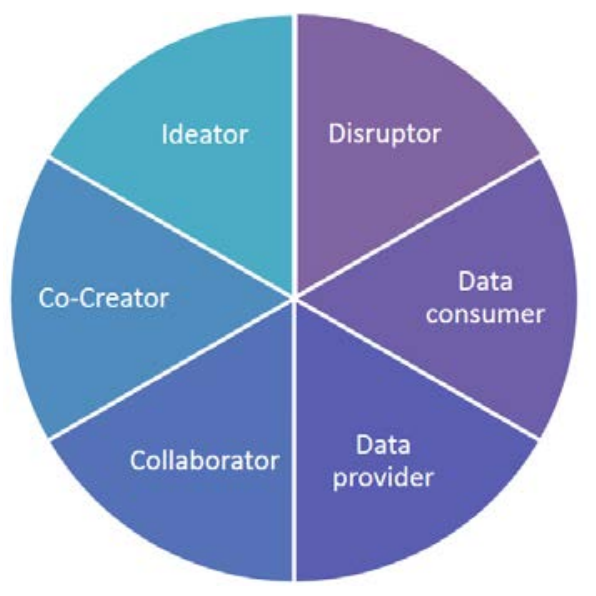

Figure 1: Palette of Participation in Participatory Sensing, adapted from [10].

Every interaction between people and civic technology is a deliberate and intentional act of public participation. As such, public participation in PS can take different forms - from the person collecting data about predefined issues (data provider); the person collaborating with authorities to monitor issues predefined by authorities (collaborator); the person cocreating solutions to address issues of shared concern (co-creator); the person who ideates civic actions (ideator); to the person who disrupts established processes by passive nonparticipation or negative participation (disruptor).

\section{ABSTRACT}

The way people participate in decision making has radically changed over the last few decades. Technology has facilitated the sharing of knowledge, ideas and opinions across social structures, and has allowed grass-root initiatives to flourish. Participatory civic technology has helped local communities embrace civic action on matters of shared concern. In this case study, we describe SENSEI, a year-long participatory sensing movement. Local community organisations, decision makers, families, individuals and researchers worked together to co-create civic technologies to help them address environmental issues of shared interest, such as invasive plant species, abandoned items in the forests and nice places. Over 240 local participants have taken part to the different stages of this year long process which included ten community events and workshops. As a result, over a hundred concrete ideas about issues of common interest were generated, nearly thirty civic tech prototypes were designed and developed, along with hundreds of environmental observations. In this paper, we describe the process or orchestration of this initiative and present key reflections from it.

\section{CCS CONCEPTS}

\section{- Human-centered computing $\rightarrow$ Field studies; Interaction design process and methods;}

\section{KEYWORDS}

civic tech; co-creation; civic participation; participatory sensing; environmental monitoring

\section{ACM Reference Format:}

Victoria Palacin, Sile Ginnane, Maria Angela Ferrario, Ari Happonen, Annika Wolff, Sara Piutunen, and Niina Kupiainen. 2019. SENSEI: Harnessing Community Wisdom for Local Environmental Monitoring in Finland. In CHI Conference on Human Factors in Computing Systems Extended Abstracts (CHI'19 Extended Abstracts), May 4-9, 2019, Glagsgow, Scotland, UK. ACM, New York, NY, USA, 8 pages. https://doi.org/10.1145/3290607.3299047

\section{INTRODUCTION}

In the past five years, $\mathrm{HCl}$ has seen a "civic turn", which has resulted in a rich body of study about the interplay between civics and technology [5, 8]. Research in the wild [12], participatory design[14], speculative design [5] and action research interventions [1] to study this interplay in community settings have increased in popularity. Current $\mathrm{HCl}$ research is facing a growing challenge to improve the quality and sustainability of research project outcomes. The field is moving away from being confined to the design and deployment of consultation technology [7] towards a process of working alongside local communities to create and deploy civic technology that addresses matters of shared concern $[2,4,13-15]$.

In this paper, we describe the process of co-creating a year long participatory sensing movement between local people, municipal officers and community organisations around environmental issues of 


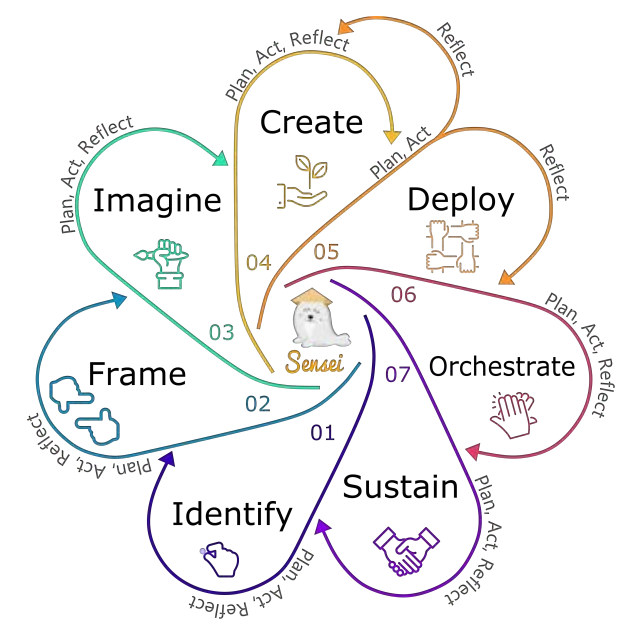

Figure 2: SENSEI Approach based on City Commons [2] and Speedplay [6]

Table 1: Stages, Goals and Outcomes

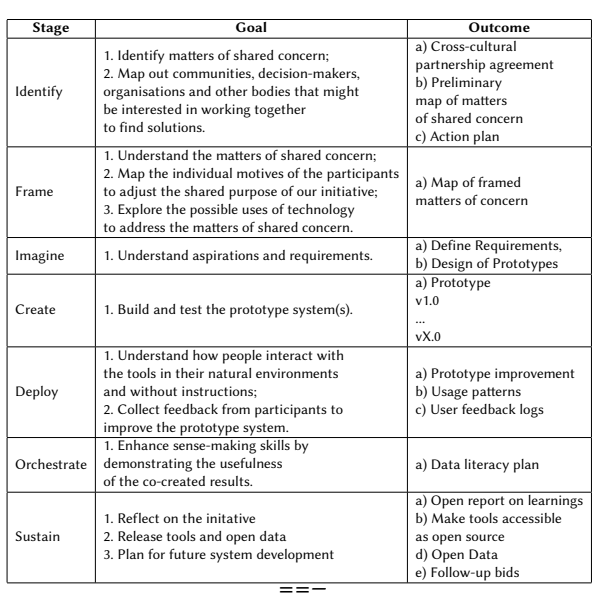

${ }^{1} \mathrm{Me}$-talo is an NGO and a community centre used for activities for everyone in town

${ }^{2}$ Liberty Bell is a field research platform using smart bycicle bells and wristbands to gain insights into the experiences of people on the move common concern. The approach focused on supporting the creation, engagement and sense-making of civic technology, while embracing different types of public participation (See Fig. 1). We used different methodological approaches (namely workshops, surveys and interviews) to get an understanding of the pressing needs of the different stakeholders, their motives for engaging with this initiative, how they imagine civic technology can be used, and how best to co-design with them. This research was done in seven stages (identify, frame, imagine, create, deploy, orchestrate and sustain) - expanding on previous work on sustainable community engagement using civic technology [2] and following an in-the-wild approach [12].

The key contributions of this paper are three-fold: (1) outline the application of $\mathrm{HCl}$ approaches to inform and orchestrate a community initiative around issues of shared concern; (2) give insights into the use of participatory sensing in nurturing and supporting long-term sustainable practices (3) outline learnings that could be helpful for future co-created environmental participatory sensing systems.

\section{THE SENSEI INITIATIVE}

SENSEI is a community initiative that aims to show how technology and participatory practices can be combined to monitor issues of shared concern, make sense of data and solve problems collectively. Officers from environmental management, neighborhood participation and services development in the municipality were involved in the entire process. ME-talo ${ }^{1}$ played the role of community coordinator. Liberty Bell ${ }^{2}$ shared their field research tools for community monitoring projects. The researchers informed and orchestrated the process of the initiative using novel research frameworks from $\mathrm{HCl}$ research [2, 6, 12]. Over 240 participants, aged 7 to 85 years, of which 212 were Finnish speakers and 28 were English speakers, were involved over a period of 10 months. Ten events and workshops generated over 100 ideas about issues of shared interest, 28 civic tech prototypes and dozens of sense-making artifacts, including data interactions, analysis of datasets and data sculptures. A platform for environmental monitoring including sensing devices, a website and apps was built during this process. This platform has been used for 90 days during 2018 by 64 people to monitor environmental issues in town.

\section{METHOD}

Our approach combined two frameworks which draw inspiration from action research, design thinking, participatory design, agile development and an in-the-wild approach: i) the city commons approach by Balestrini M. [2] and ii) the Speedplay framework by Ferrario M.A. [6]. The city commons is a novel approach to orchestrate community engagement around issues of shared concern, enhancing community ownership, openness, skills development and prompting discussions about data privacy, ownership and governance [2]. Whereas the Speedplay framework enables the development of 


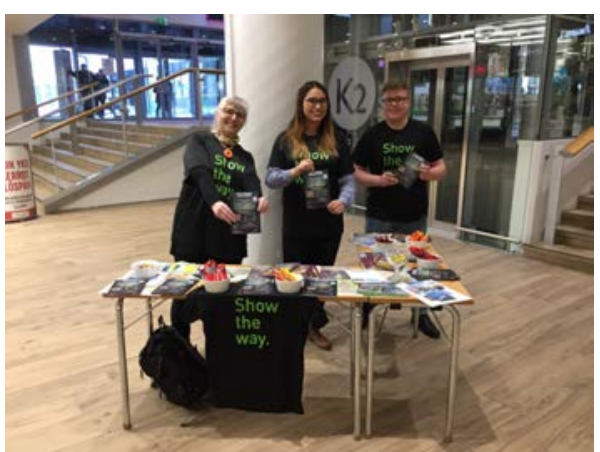

Figure 3: Public conversations at a pop-up shop in the main city shopping centre

Table 2: Top 10 emerging ideas about issues of interested (generated using dataBASIC.io)

\begin{tabular}{|l|c|}
\hline Top Word & Frequency \\
\hline Places & 31 \\
\hline Species & 22 \\
\hline Street & 19 \\
\hline Outdoor & 16 \\
\hline Abandoned & 14 \\
\hline Trash & 11 \\
\hline Free & 5 \\
\hline Snow & 5 \\
\hline Roads & 5 \\
\hline Broken & 4 \\
\hline
\end{tabular}

software in a rapid and agile manner with an emphasis on participatory reflection [6]. We saw an opportunity to combine the orchestration features from the city commons with the technical advantages of Speedplay to engineer technologies using agile development iterations. As a result, the initiative followed seven stages in an iterative manner (see Fig 2). Goals and outcomes for each of the stages are detailed in Table 1.

\section{Stage 1: Identify (3 months)}

This stage was focused on i) identifying matters of shared concern and ii) mapping out communities, decision-makers, organisations and other bodies that might be interested in working together to find solutions $[2,9]$. The following activities were carried out:

- Online mapping of matters of shared concern: The researchers mapped online conversations on discussion forums, news and social media to create a preliminary understanding of the issues in town. These discussions had increased around environmental issues, such as smells and pollution, in the last 3 years.

- Local stakeholder identification: A preliminary meeting was set up with municipal officers to understand their work and challenges. The matters mapped in the previous activity provided a good focus for discussion about their relationship with local people. This meeting led to the creation of a list of existing associations, community groups and municipal offices that could be interested in working together to find solutions for issues of shared concern. Subsequently, these potential stakeholders were contacted

- Partnership Conversations: Direct phone calls, emails and partnership meetings with stakeholders - a range of neighborhood associations, municipal offices, NGOs and community groups - led to: (1) the creation of an initial map of existing municipal priorities, which included issues such as smells, noise, alien plant species, blue algae and litter; (2) commitments for future actions, through a cross-cultural partnership agreement [11], which articulated our common intentions, actions and goals including specific responsibilities, ethical and legal guidelines. This agreement allowed the initiative to continue despite the lack of official funding, because every partner committed to provide some resources for the initiative, including expertise, time and materials; (3) a plan of public activities, including workshops and public conversations, in order to open the initiative to everyone and help reach a common understanding of the shared matters of concern in the local community.

- Public Conversations: This activity entailed talking to people in places where they congregate. Municipal officers, individual volunteers and the researchers set up a pop-up shop in the city's shopping centre and mingled with people (see Fig3) talking about their concerns about local environmental issues and inviting them to upcoming initiative events. 


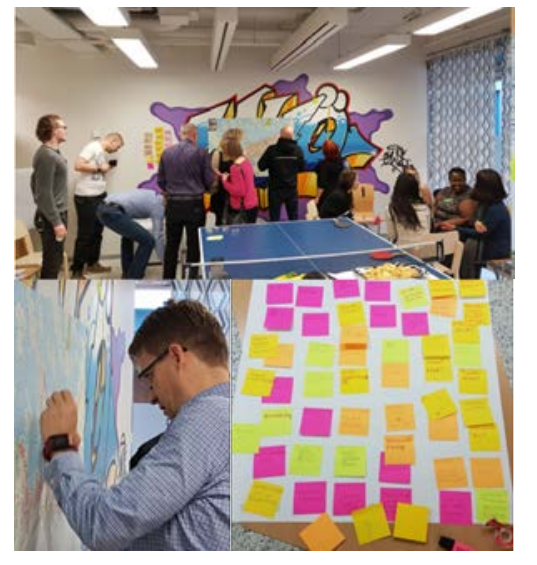

Figure 4: Ideation workshop

The workshop programme included activities of: i) Introduction and ice-breaking; ii) Rapid ideation: Produce as many ideas as possible, pin them on a large scale wall map, share your thoughts with others; iii) Charettes about "What are the matters of concern you would like to monitor in town?", "Why are they important for you?"; iv) Reverse thinking about "How would you monitor matters of concern if technology did not exist?".

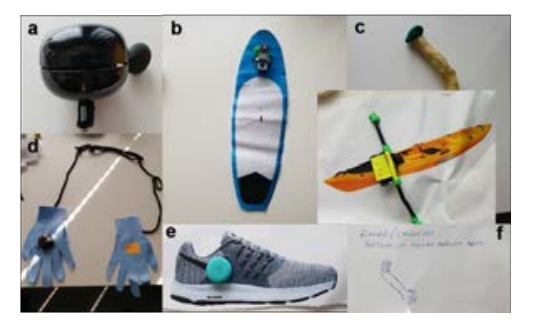

Figure 5: Prototypes for Outdoors

\section{Stage 2: Frame (1 month)}

The aim of this stage was to i) understand the matters of shared concern, ii) map the individual motives of the participants to adjust the shared purpose of our initiative and iii) explore the possible uses of technology to address the matters of shared concern. This stage included co-creation workshops, where a number of design thinking and scenario techniques [3] were combined. The techniques used in this stage were selected to boost ideation, deliberation and creativity among participants. They included introductions and icebreakers, rapid ideation, charrette discussions and reverse thinking.

Ideation Workshops: Two workshop open days were organised at the community centre (ME-talo) to continue identifying matters of common concern and deepen the understanding of those issues. The facilitators were municipal officers, individual volunteers and the researchers. Over 50 people attended these events in total.

As a result over 100 suggested matters of concern resulted from brainstorming (see Table 2). These ideas were analysed and grouped together into 10 main matters of concern. Participants often illustrated ideas by providing examples from their day to day experiences. It quickly became apparent that environmental issues - positive and negative - were of greater interest to participants over other topics (See Table 2). For example, sharing knowledge about good places in town was a popular idea. Negative issues such as abandoned items and litter were often suggested.

\section{Stage 3: Imagine (1 month)}

The goal here was to understand the participants' aspirations and requirements. This was achieved through co-creation workshops that drew basis from design thinking, user-centred design and participatory design.

Prototyping Workshops Two open workshop days were organised at the community centre (MEtalo) to co-design technology prototypes that would focus on the identified matters of shared concern. These workshops followed similar organization structure as the framing workshops. Over 50 people attended these events in total. The workshop programme included rolestorming and prototyping.

28 prototypes were developed by the participants. These prototypes included i) wearables for hand, foot, arm, wrist, head; ii) mobile apps; iii) attachment to other things e.g. headphones, necklaces, gloves, paddle-boards, paddles, bracelets, walking sticks, steering wheels; iv) characters e.g. a remote duck to monitor algae, a virtual pet dragon, a neighborhood watch cat (see Figures 6, 7, 5). We quickly realised that mobile applications were a common denominator to all these prototypes - participants would often describe their prototypes as part of a platform which they could access from their own smart devices. 


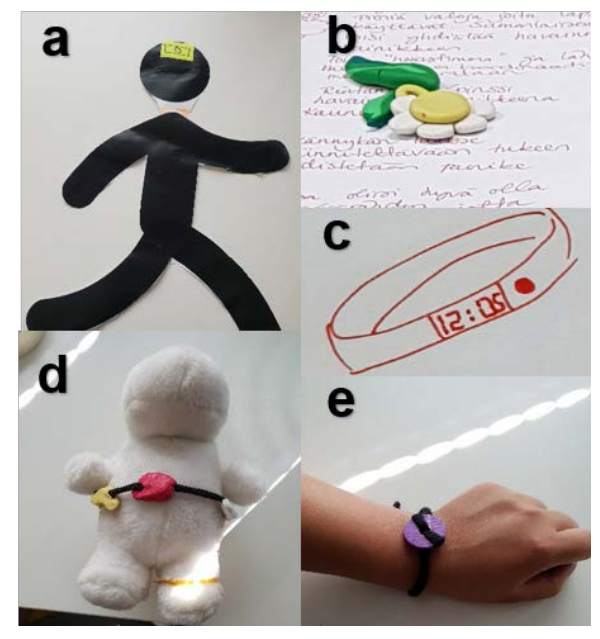

Figure 6: Wearable Prototypes

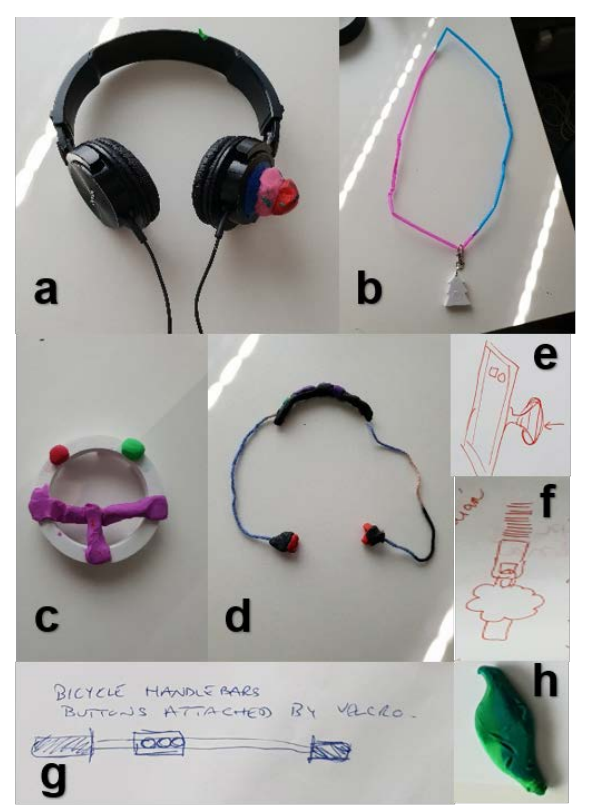

\section{Stage 4: Create (4 months)}

Prior to commencing Stage 4, in selecting the issues of shared concern, we needed to strike a balance between the issues participants had highlighted in the workshops and issues the municipal environmental office were tasked with monitoring. As a result, the chosen issues were: invasive plant species, nice places in town and abandoned items in nature (aka illegal landfills).

In this stage the tools needed to address the chosen matters of shared concern were created. Participants critiqued and pilot tested the prototypes. An Agile approach for prototype development was taken with ten days long iterations. As a result, the SENSEI platform was created - a platform using front-end bluetooth devices such as bicycle bells, wristbands and sticky buttons (see Fig 8) which participants could press to report an issue e.g: one click = invasive plants; two clicks = nice place; hold 3sec = abandoned items. These devices were connected to a mobile application (see Fig 9) that allowed participants to submit photos and create private monitorings.

\section{Stage 5: Deploy (3 months)}

The created technology was deployed in the wild and iteratively improved. Stage 5 allowed us to understand how participants interacted with the technology in their everyday life without instructions. A total of 64 locals volunteered to use SENSEI over a period of 12 weeks. This pool of participants included local people who had attended the workshops, others who were recruited by the workshop participants themselves and those who had heard about the initiative from the partners. A total of 300 observations were recorded on SENSEI.

\section{Stage 6: Orchestrate (Continuous)}

Meet-ups were regularly organised with participants to discuss their concerns and gather feedback about the platform. Educational materials about the issues being monitored were distributed by post directly to the participants. A public interactive exhibition was organised to support sense-making with civic data. The data collected in the SENSEI platform was used to create several 'urban data games' designed to familiarise people with the datasets collected through social interactions, both direct interaction through conversation or indirect interactions through text or data artefacts left in public view.

\section{Stage 7: Sustain (2 months)}

A workshop to discuss the future of SENSEI was organised with the participants. The discussions focused on technical improvements and new civic actions. The participants co-created a report on the data collected by SENSEI assisted by researchers and the report will be brought to municipal decision-makers to inform their work. 


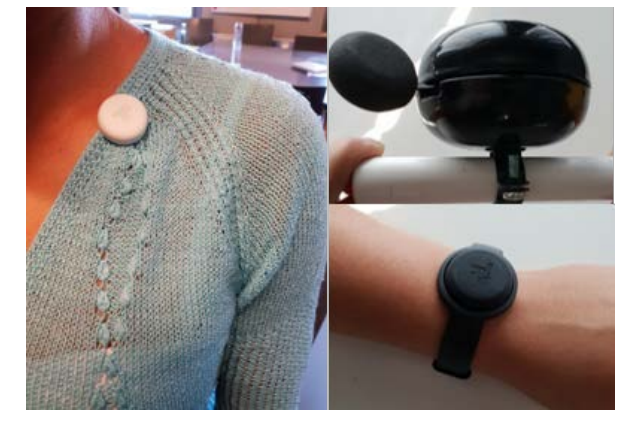

Figure 8: SENSEI deployed devices

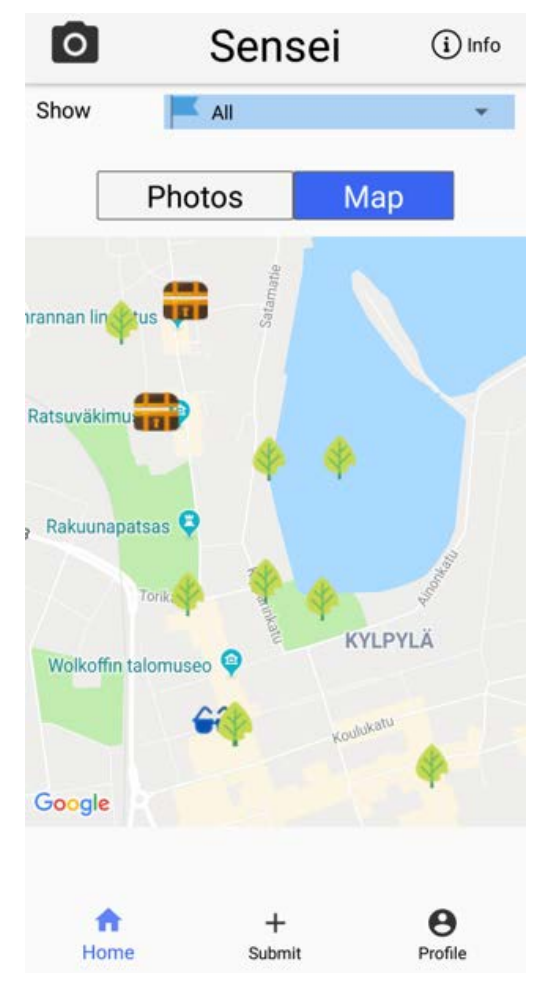

Figure 9: SENSEI application

${ }^{3}$ IAP2: Spectrum of Public Participation www. iap2.org

\section{LESSONS LEARNED AND KEY REFLECTIONS}

- Face-to-face multi-constituency communication sustains engagement: Direct communication with the participants and decision-makers involved helped raise awareness about the approach, enhanced public engagement and resulted in clear commitments by all those involved. The workshops allowed consensus to be reached as differences arose over the selection of what should be monitored. Giving communities a voice is a powerful way of harnessing their wisdom. However it also means that expectations need to be managed in a timely way.

- Welcome different types of participation: Over the course of the Identification stage, it became clear that individuals wished to get involved at different levels. Some were interested in the workshops, whereas others wanted to get immediate access to tools. As a result, we had to re-organise our call for public participation into two strands: i) those wishing to get involved in the workshops, and ii) those wishing to use the resulting creations for civic action. It was important to be flexible and allow for changing dynamics over the course of the process. Designing for different (often temporal and parallel) levels of participation (as acknowledged by frameworks such as IAP ${ }^{3}$ ) is key to begin to understand the affordances of participatory sensing technologies in the wild.

- Participatory sensing should be designed for diversity across all ages, genders and skillsets: All events were organised to be as inclusive as possible. Workshops were held in both Finnish and English and balanced the teamwork of participants of all ages, genders and skillsets. As a result a common understanding with all participants was built organically.

- Identify and fill gaps with know-how from experts: In co-creating technology, it is useful to identify and fill any gaps in required technical skills. During the Imagine stage, participants came up with several prototype ideas which required specific technical skills outside of our core skillset. Liberty Bell got involved with a number of devices for the monitoring campaign. Students worked on the development of the platform and members of the community designed and printed 3D models of the prototypes which allowed us to evaluate the prototypes' suitability.

- Enhance sense-making skills by using civic data: Our public exhibition helped familiarise people with the datasets collected through playful interactions.

- Enhance the sense of ownership by welcoming critique and suggestions: Pilot testing with participants in a real-world context is useful for detecting bugs and improving civic tech but also for enhancing a sense of common ownership. Participants actively tested, critiqued and suggested improvements to SENSEI. They also named each of the platform releases. 


\section{CONCLUSION}

In this paper, we describe the process and orchestration of the SENSEI initiative and present key reflections from it. Local community organisations, decision makers, families, individuals and researchers worked together to co-create civic technologies to help them address environmental issues of shared interest, such as invasive plant species, abandoned items in the forests and nice places.

The public participation continuum continues to evolve, largely due to the rise in civic-tech which has facilitated activism, public campaigning and community monitoring. Technology has opened up a myriad of communication channels between municipal decision-makers and the community they serve. Civic technology and participatory sensing in particular, allows local governments to use civic intelligence to identify common causes.

Limited public resources and services can act as a barrier to implementing solutions to the problems identified. Creators of civic participatory technology should actively seek involvement and cooperation from decision-makers in order to ensure that the supports and infrastructure are in place to allow innovations to flourish and from which the community can truly benefit.

\section{ACKNOWLEDGMENTS}

We would like to thank all the volunteers, partners, and authors who wrote and provided helpful comments on previous versions of this document. We gratefully acknowledge the support from the Finnish Cultural Foundation for South Karelia Region and the PERCCOM programme.

\section{REFERENCES}

[1] Mara Balestrini, Jon Bird, Paul Marshall, Alberto Zaro, and Yvonne Rogers. 2014. Understanding Sustained Community Engagement: A Case Study in Heritage Preservation in Rural Argentina. Proceedings of the 2014 CHI Conference on Human Factors in Computing Systems (2014).

[2] Mara Balestrini, Yvonne Rogers, Carolyn Hassan, Javi Creus, Martha King, and Paul Marshall. 2017. A city in common: a framework to orchestrate large-scale citizen engagement around urban issues. In Proceedings of the $2017 \mathrm{CHI}$ Conference on Human Factors in Computing Systems.

[3] Susanne Bodker. 1999. Scenarios in user-centred design-setting the stage for reflection and action. In Proceedings of the 32nd Annual Hawaii International Conference on Systems Sciences. IEEE.

[4] Saskia Coulson, Mel Woods, Michelle Scott, Drew Hemment, and Mara Balestrini. 2018. Stop the Noise! Enhancing Meaningfulness in Participatory Sensing with Community Level Indicators. In Proceedings of the 2018 on Designing Interactive Systems Conference 2018. ACM.

[5] Carl DiSalvo, Tom Jenkins, and Thomas Lodato. 2016. Designing speculative civics. In Proceedings of the $2016 \mathrm{CH}$ Conference on Human Factors in Computing Systems. ACM.

[6] Maria Angela Ferrario, Will Simm, Stephen Forshaw, Adrian Gradinar, Marcia Tavares Smith, and lan Smith. 2016 Values-first SE: research principles in practice. In Proceedings of the 38th International Conference on Software Engineering Companion. ACM, 553-562.

[7] Connie Golsteijn, Sarah Gallacher, Licia Capra, and Yvonne Rogers. 2016. Sens-Us: Designing Innovative Civic Technology for the Public Good. In Proceedings of the 2016 ACM Conference on Designing Interactive Systems. ACM, 39-49.

[8] Ian G Johnson, John Vines, Nick Taylor, Edward Jenkins, and Justin Marshall. 2016. Reflections on Deploying Distributed Consultation Technologies with Community Organisations. In Proceedings of the 2016 CHI Conference on Human Factors in Computing Systems. ACM.

[9] Bruno Latour. 2004. Why has critique run out of steam? From matters of fact to matters of concern. Critical inquiry 30, 2 (2004).

[10] Maria Palacin-Silva and Jari Porras. 2018. Shut up and take my environmental data! A study on ICT enabled citizen science practices, participation approaches and challenges.. In ICT4S.

[11] Cross-Cultural Partnership project. 2018. Cross-Cultural Partnerships: Towards Connected Knowledge. http:// connected-knowledge.net/. (Accessed on 09/17/2018).

[12] Yvonne Rogers and Paul Marshall. 2017. Research in the Wild. Synthesis Lectures on Human-Centered Informatics 10, 3 (2017).

[13] Will Simm, Jon Whittle, Rod Dillon, Jen Southern, and Maria-Angela Ferrario. 2013. Co-Designing With and For Chaotic Lives : \# Patchworks, a Catalyst Case. In Proceedings of the 2013 CHI Conference on Human Factors in Computing Systems.

[14] Chelsea-joy Wardle, Mitchell Green, Christine Wanjiru Mburu, Melissa Densmore, Cape Town, and South Africa. 2018 Exploring Co - design with Breastfeeding Mothers. In Proceedings of the $2018 \mathrm{CHI}$ Conference on Human Factors in Computing Systems.

[15] Annika Wolff, Alan-Miguel Valdez, Matthew Barker, Stephen Potter, Daniel Gooch, Emilie Giles, and John Miles. 2017. Engaging with the Smart City Through Urban Data Games. In Playable Cities. Springer. 